\title{
Carreras administrativas en Chile, 1884-1920 ¿PATRONAZGO O CARRERAS BUROCRÁTICAS? ${ }^{1}$
}

\begin{abstract}
RESUMEN
Tanto contemporáneos como historiadores han criticado la administración pública del periodo parlamentario chileno debido al desarrollo de prácticas de patronazgo en el nombramiento de empleados públicos. Sin embargo, gran parte de esas interpretaciones no se basan en evidencia. Este artículo analiza el desarrollo de carreras administrativas en servicios públicos entre 1884 y 1920. En específico, se estudian los procesos de nombramiento y promoción. Se concluye que, a pesar de no existir un marco burocrático para la gestión de carreras, en la práctica surgió un sistema de servicio civil de facto. Este permitió desarrollar carreras administrativas largas dentro de los servicios públicos.
\end{abstract}

Palabras claves: Chile, siglo XIX, siglo Xx, servicio civil, administración pública, burocracia, empleados públicos.

\begin{abstract}
Historians and contemporaries alike have criticized Chilean public administration during the Parliamentary period due to the emergence of clientelism in the selection of public workers. Notwithstanding, a great part of these impressions are not based on evidence. This article analyzes the development of administrative careers in public services between 1884 and 1920, specifically studying the hiring and promotion processes. It concludes that, despite the nonexistence of a bureaucratic framework for career management, in practice there was a de facto civil service system which permitted long administrative careers within public administration.
\end{abstract}

Keywords: Chile, Nineteenth Century, Twentieth Century, Civil Service, Public Administration, Bureaucracy, Civil Servants.

Recibido: Julio 2017.

Aceptado: Noviembre 2017.

\footnotetext{
* Doctor en Historia, Universiteit Leiden. Director y profesor asociado del Departamento de Gestión y Políticas Públicas de la Universidad de Santiago de Chile. Correo electrónico: diego.barria@usach.cl

${ }^{1}$ Este artículo es resultado del proyecto Fondecyt de Iniciación $N^{\circ} 11140348$ : "Reforma administrativa del Estado chileno entre 1920 y 1931: ¿Nuevos proyectos o herencias del pasado?”.
} 


\section{INTRODUCCIÓN}

Comparado con sus pares latinoamericanos, el Estado chileno ha sido destacado por una serie de estudios por sus altos niveles de capacidad institucional ${ }^{2}$. Miguel Ángel Centeno y Agustín Ferraro plantean que Chile y Costa Rica son los únicos países latinoamericanos que cuentan con una administración autónoma y con un servicio civil de carrera ${ }^{3}$. En gran parte, esto se debe a un desarrollo de la administración en el largo plazo. De hecho, ya desde el siglo XIX estos rasgos distintivos eran claros ${ }^{4}$.

No obstante, a lo largo del siglo XIX se presentaron duras críticas al funcionamiento de la administración pública chilena, especialmente por considerarse que primaban el nepotismo y la contratación en empleos públicos de protegidos políticos ${ }^{5}$. Esta crítica tomó fuerza a mediados de la década de 1880, de la mano del crecimiento del empleo público. En 1884, el periodista Juan Rafael Allende declaró que en Chile había surgido una nueva profesión, la de empleado público. En su opinión: "Un rosario de decretos creando oficinas, empleados, sueldos, me asegura que antes de mucho hasta yo seré empleado público" ". La idea que se instaló fue que estos puestos se crearon para servir favores políticos, y que para obtener uno se requería contar con influencias en el poder? En las primeras décadas del siglo xx, intelectuales como Francisco Encina y Tancredo Pinochet criticaron a los empleados, por considerarlos parásitos ${ }^{8}$ e incompetentes ${ }^{9}$.

En la historiografía chilena también existen visiones divergentes respecto al funcionamiento de la administración pública y sus empleados. Para Gabriel Salazar, a fines del siglo XIX, los empleos tenían un carácter inestable, debido a la existencia de la empleomanía ${ }^{10}$. De modo contrario, otros historiadores plantean que durante el siglo XIX existió estabilidad en los empleos. Por ejemplo, Julio Heise, a partir de una comparación del número de directores de Correos y de la Dirección General de Bibliotecas, Archivos y Museos entre 1861-1925 y 1925-1972, afirma que en el periodo parlamentario los funcionarios duraban más tiempos en sus cargos, lo que mostraría, en su opinión, que durante esa época se respetaba la carrera funcionaria, hecho que no ocurrió, según él,

\footnotetext{
${ }^{2}$ Véase Miguel Ángel Centeno, Blood and Debt. War and the Nation-State in Latin America, University Park, The Pennsylvania University Press, 2002; Marcus Kurtz, Latin American State Building in Comparative Perspective. Social Foundations of Institutional Order, New York, Cambridge University Press, 2013; David H. Soifer, State Building in Latin America, New York, Cambridge University Press, 2015.

${ }^{3}$ Miguel Ángel Centeno \& Agustín Ferraro, "Republics of Possible: State Building in Latin America and Spain”, in Miguel Ángel Centeno \& Agustín Ferraro (eds.), State and Nation Making in Latin American and Spain. Republics of the Possible, New York, Cambridge University Press, 2013, pp. 3-24.

${ }^{4}$ Centeno, op. cit.

${ }^{5}$ Mario Góngora, Ensayo histórico sobre la noción de Estado en Chile en los siglos XIX y XX, Santiago, Editorial Universitaria, 1986, p. 54.

6 "Una Nueva Profesión”, Padre Padilla, Santiago, 4 de octubre de 1884.

${ }^{7}$ Diego Barría, "Representaciones en Torno a los Empleados Públicos en Chile, 1880-1920", en Revista de Historia y Geografia, No 35, Santiago, 2016, p. 69.

${ }^{8}$ Francisco Encina, Nuestra inferioridad económica, Santiago, Editorial Universitaria, 1972 [1911], pp. 78-79, 163-164.

${ }^{9}$ Tancredo Pinochet, Un año empleado público en Chile, Santiago, Imprenta Universitaria, 1915, p. 11.

${ }^{10}$ Gabriel Salazar y Julio Pinto, Historia contemporánea de Chile IV. Hombría y feminidad, Santiago, LOM Ediciones, 1999, p. 88.
} 
después de $1925^{11}$. En la misma línea, Francisco Antonio Encina ${ }^{12}$ y Alberto Edwards Vives $^{13}$ afirman que, si bien los ministros eran aves de paso, existió un grupo de empleados que gozó de estabilidad en sus puestos, principalmente subsecretarios y jefes de sección, cuestión que permitió que las oficinas públicas continuaran con la "correcta y expedita marcha que la administración traía desde los días de Portales, Rengifo y Tocornal"14.

En términos simples, la discusión entre estos autores apunta a si los sistemas de gestión de personal respondían a lógicas propias del patronazgo y sistema de botín o si, por el contrario, durante el siglo XIX existió un sistema de carrera administrativa estable, asociado a la concepción weberiana de la burocracia. Por lo general se reconoce que el sistema de carrera en la administración pública chilena surgió en la década de 1920, en especial durante el primer gobierno de Carlos Ibáñez del Campo (1927-1931) ${ }^{15}$. Adicionalmente, se considera que a través de las distintas versiones del estatuto se establecieron criterios de ingreso y mecanismos de ingreso y ascenso basados en el mérito y la antigüedad ${ }^{16}$. A la vez, se destaca que quienes ocuparon cargos directivos en la administración durante el siglo xx lo hicieron tras largas carreras administrativas ${ }^{17}$. Sin embargo, a la luz de lo planteado por autores como Julio Heise ${ }^{18}$, resulta relevante someter a evaluación lo que, hasta hoy, se acepta en la historiografía chilena como cuestiones ciertas.

¿Qué se sabe sobre los empleados públicos durante el siglo XIX? En el caso chileno, durante la primera mitad del siglo XIX se dieron algunos avances en materia de conformación de lo que podría considerarse una burocracia. Sin embargo, la variación entre norma y realidad ${ }^{19}$ hace pensar que la burocratización fue un fenómeno creciente que se consolidó únicamente en la década de 1880, a través de la reforma casi completa de la administración y el crecimiento del número de empleados en las décadas siguientes ${ }^{20}$. La literatura también ha mostrado que estos empleados fueron criticados por su peso en el padrón electoral ${ }^{21}$, y por su origen social ${ }^{22}$. De hecho, entre 1880 y 1920, en la opi-

\footnotetext{
${ }^{11}$ Julio Heise, Historia de Chile. El Periodo Parlamentario, 1861-1925, Santiago, Editorial Andrés Bello, 1972, tomo I, pp. 301-306.

${ }^{12}$ Francisco Encina, Historia de Chile, Santiago, Editorial Nascimento, 1951, tomo Xx.

${ }^{13}$ Alberto Edwards Vives, La fronda aristocrática en Chile, Santiago, Editorial Universitaria, 1982 [1928], pp. 159, 198, 209.

${ }^{14}$ Encina, Historia..., op. cit., pp. 342-343.

${ }_{15}$ Adolfo Ibáñez Santa María, Herido en el ala. Estado, oligarquías y subdesarrollo. Chile 1924-1960, Santiago, Biblioteca Americana, 2003.

${ }^{16}$ Arturo Valenzuela, "Parties, Politics and the State in Chile. The Higher Civil Service", in Ezra Suleiman (ed.), Bureaucrats and Policy Making, New York, Holmes and Meier, 1984, pp. 242-279.

${ }_{17}$ Rafael López-Pintor, Development Administration in Chile. Structural, Normative, and Behavorial Constraints to Performance, PhD thesis, Chapell Hill, University of North Carolina at Chapell Hill, 1976.

${ }^{18}$ Heise, op. cit., pp. 301-306.

${ }^{19}$ Elvira López, El proceso de construcción estatal en Chile. Hacienda pública y burocracia (1817-1860), Santiago, Ediciones de la Dirección de Bibliotecas, Archivos y Museos, Centro de Investigaciones Diego Barros Arana, colección Sociedad y Cultura, 2015, vol. LVII, p. 265.

${ }^{20}$ Diego Barría, "Rasgos burocráticos en las reformas administrativas en el Chile de la década de 1880", en Historia Crítica, N 56, Bogotá, 2015, pp. 61-84.

${ }^{21}$ Diego Barría, "Empleados públicos y clase media, Chile 1880-1920: un análisis exploratorio a partir de cifras oficiales", en Revista de Historia y Geografia, №32, Santiago, 2015, p. 86.

${ }^{22}$ César de León, "Las capas medias en la sociedad chilena del siglo XIX", en Anales de la Universidad de Chile, $\mathrm{N}^{\circ}$ 132, Santiago, 1964, pp. 51-95; María Rosaria Stabili, "Jueces y justicia en el Chile liberal”,
} 
nión pública aparecieron diversos reproches contra empleados públicos, que apuntaron tanto a la calidad de su trabajo como a sus hábitos de vida. En respuesta a esto, los funcionarios hicieron esfuerzos por construir una identidad laboral que les permitiera ser considerados personas decentes ${ }^{23}$.

Durante el periodo colonial, la compra de cargos administrativos fue una constante. Desde la década de 1750 en adelante, los Borbones buscaron terminar con la relación entre funcionarios y las élites locales. Para ello, comenzaron a nombrar funcionarios peninsulares, que desarrollaban carreras en América antes de volver a la Metrópoli. De esta forma, hacia la década de 1780 en las audiencias americanas existía un sistema de carreras basado en los ascensos de funcionarios con experiencia ${ }^{24}$. Adicionalmente, los Borbones instauraron el sistema de intendencias ${ }^{25}$. De acuerdo con David Soifer, tras las reformas borbónicas, se instauraron en América sistemas burocráticos con procedimientos formales y con requisitos específicos para el nombramiento de funcionarios ${ }^{26}$. Así, en las colonias y posteriores países independientes se fueron formando cuerpos de empleados civiles con carreras largas. Por ejemplo, hasta 1821 no era extraño encontrar en México funcionarios con carreras de entre diez y treinta años ${ }^{27}$. No obstante, esto no fue un patrón común. Más bien, lo que primó fue la conformación de aparatos burocráticos dependientes de decisiones políticas. Por ejemplo, en América Central, salvo el caso de Costa Rica, se conformaron burocracias no profesionales, habitadas por empleados nombrados por razones políticas ${ }^{28}$. Incluso, en casos en los que emergieron burocracias profesionales, como en los sectores salud y educación en Argentina a partir de 1880, estos cuerpos profesionales convivieron con una administración permeada por camarillas en competencia por el control del Estado ${ }^{29}$.

Elvira López, por su parte, analiza la conformación de un cuerpo de funcionarios en Chile entre 1817 y 1860 . Ella identifica para 1826 casos de funcionarios con más de diez años de servicios, algunos, incluso, sobre cuarenta y cincuenta ${ }^{30}$. Otros casos son Santiago Lindsay, director de la Oficina de Estadísticas o Ramón Vial, Inspector General de Telégrafos, quienes estuvieron al frente de sus instituciones por, aproxima-

en Marcello Carmagnani (ed.), Constitucionalismo y orden liberal. América Latina 1850-1920, Torino, Otto Editore, 2000, pp. 227-257.

${ }^{23}$ Diego Barría, “An Honourable Profession: Public Employees and Identity Construction in Chile, 18801920", in Bulletin of Latin American Research, en prensa: https://doi.org/10.1111/blar.12836 (early view).

${ }^{24}$ Mark Burkholder y D.S. Chandler, De la impotencia a la autoridad, México, Fondo de Cultura Económica, 1984, p. 183.

${ }^{25}$ John Lynch, Administración colonial española. 1782-1820. El sistema de intendencias en el virreinato del Río de la Plata, Buenos Aires, EUDEBA, 1962; John Fisher, Gobierno y sociedad en el Perú colonial: el régimen de intendencias, 1784-1814, Lima, Pontificia Universidad Católica del Perú, 1981; Horst Pietschmann, Las reformas borbónicas y el sistema de intendencias en Nueva España. Un estudio político administrativo, México, Fondo de Cultura Económica, 1996.

${ }^{26}$ Soifer, op. cit, , pp. 84-85.

${ }^{27}$ Omar Guerrero, Historia del Servicio Civil de Carrera en México, México, Miguel Ángel Porrúa, 2011, p. 118.

${ }^{28}$ James Mahoney, "Militarization without Bureaucratization in Central America", in Centeno \& Ferraro (eds.), State and Nation Making..., op. cit., pp. 222-223.

${ }^{29}$ Ricardo Salvatore, "Between Empleomanía and the Common Good: Expert Bureaucracies in Argentina (1870-1930)", in Centeno \& Ferraro (eds.), State and Nation Making..., op. cit. pp. 225-246.

${ }^{30}$ López, op. cit., p. 219. 
damente, veinte años cada uno ${ }^{31}$. Salvo lo que plantean estos trabajos, poco se sabe de los funcionarios públicos del siglo XIX chileno a partir de trabajo de archivos. Lo que sí hay son opiniones sobre el punto que son contradictorias entre sí. Este artículo aborda la cuestión de la selección de empleados públicos y desarrollo de carreras administrativas en Chile entre 1884 y 1920. En específico, se utilizan rasgos característicos de la burocracia weberiana -puntualmente el marco normativo sobre empleo público, la duración de carreras y las formas de nombramiento- para determinar si los funcionarios podían desarrollar carreras administrativas o si, por el contrario, el empleo público estaba dominado por la inestabilidad y el favor político. Para ello, se analizan nombramientos y ascensos en tres oficinas públicas: la Dirección de Contabilidad, el Tribunal de Cuentas (que en 1888 reemplazó a la Contaduría Mayor) y la Dirección de Impuestos Internos. Se seleccionaron estas oficinas de la Hacienda Pública, pues este sector es reconocido por la literatura como el primer foco de desarrollo burocrático ${ }^{32}$. De hecho, estas oficinas realizaban tareas tradicionalmente consideradas "burocráticas", como registrar actos, juzgar el uso de los recursos fiscales y recaudar impuestos. En segundo término, la selección responde al hecho que el Archivo del Ministerio de Hacienda (en adelante AMH) del Archivo Nacional Histórico de Chile y del Archivo Nacional de la Administración cuenta con abundante información de la vida de estas oficinas sistematizada en tomos para cada año, lo que permitió hacer un seguimiento de las carreras de sus funcionarios.

La evidencia que se presenta a continuación muestra que, a pesar de no existir un marco normativo para el empleo público con las características propias de la burocracia weberiana, en la práctica la carrera administrativa de tipo burocrático funcionó de facto. Ello gracias a que la forma de hacer nombramientos y promociones de empleados permitió asegurar estadías largas en las oficinas públicas, incluso dando la posibilidad a funcionarios de carrera de llegar a ejercer cargos directivos.

\section{FunCIONARIOS PÚBLICOS:}

ENTRE EL PATRONAZGO Y LA BUROCRACIA WEBERIANA

En la literatura existe un abundante debate en torno a los funcionarios públicos. Algunas miradas se centran en el nivel de politización del cuerpo de funcionarios ${ }^{33}$ o su nivel

\footnotetext{
${ }^{31}$ Andrés Estefane, "Burócratas ambulantes. Movilidad y producción de conocimiento estadístico en Chile, 1860-1873", en Revista Enfoques. Ciencia Política y Administración Pública, vol. XI, No 17, Santiago, 2012, pp. 123-146; John Johnson, Pioneer Telegraphy in Chile, 1852-1876, Stanford, Stanford University Press, 1948, p. 85.

${ }^{32}$ Max Weber, Economía y sociedad, México, Fondo de Cultura Económica, 1992, p. 729; Ellen Trimberger, Revolutions from Above: Military Bureaucrats and Development in Japan, Turkey, Egypt, and Peru, New Brunswick, Transaction, 1978, pp. 67-75; Theda Skocpol, States and Social Revolutions: A Comparative Analysis of France, Russia, and China, Cambridge, Cambridge University Press, 1979, p. 50.

${ }^{33}$ B. Guy Peters \& Jon Pierre, "Politicization of the Civil Service: Concepts, Causes, Consequences", in B. Guy Peters \& Jon Pierre (eds.), Politicization of the Civil Service in Comparative Perspectives. The Quest for Control, London, Routledge, 2004, pp. 1-13.
} 
de participación en procesos de toma de decisiones ${ }^{34}$. También hay quienes distinguen entre funcionarios políticos -que desarrollan funciones políticas de representación, como los parlamentarios, por ejemplo-, ciudadanos-funcionarios -quienes participan en cuerpos de decisión, pero no reciben remuneración por su trabajo sino que lo realizan como un deber cívico- y los servidores públicos o personal administrativo -que desarrollan trabajo intelectual en oficinas ${ }^{35}$. Otra línea de trabajos se centra en los sistemas de personal. Leonard White los definió como el conjunto de leyes, reglas, regulaciones, decisiones judiciales y costumbres que prevalecen en una jurisdicción ${ }^{36}$. Hans Bekke, James Perry y Theo Toonen los definen como las instituciones encargadas de movilizar recursos humanos para los fines del Estado. En específico, importan las reglas formales e informales que inciden en ese proceso, cómo ellas operan y cómo perduran ${ }^{37}$. Junto a la institucionalidad, la atención se ha puesto en entender quiénes son estos empleados ${ }^{38}$.

El servicio civil, generalmente, es concebido como "un curso de profesionalización que está regido por requisitos de ingreso, estabilidad y promoción, verificado por medio de exámenes de idoneidad para el ingreso, los ascensos y la permanencia. Implica un proceso de formación continua, porque la estabilidad otorga seguridad de empleo, pero exige un desempeño con calidad gradual y periódicamente evaluado" ${ }^{\text {". }}$. Esta definición tiende a asociar el servicio civil con las características de la burocracia weberiana. Para Max Weber, la burocracia puede ser definida a partir de los siguientes rasgos: 1) una organización basada en sectores jurisdiccionales estables y contar con un personal organizado en base a normas legales o administrativas; 2) la existencia de una jerarquía de mando clara; 3) la actuación a partir de documentos escritos, los que junto a los funcionarios forman una "repartición"; 4) la administración de un cargo es una tarea especializada; 5) esa tarea especializada es de dedicación exclusiva, creando así las carreras administrativas y 6) los cargos se fundan a partir de normas generales, estables, precisas y que pueden ser aprendidas ${ }^{40}$.

\footnotetext{
${ }^{34}$ Véase, por ejemplo, Hugh Heclo, Modern Social Politics in Britain and Sweden: From Relief to Income Maintenance, New Haven, Yale University Press, 1974; Stephen Krasner, Defending the National Interest: Raw Materials Investments and US Foreign Policy, Princeton, Princeton University Press, 1978; Margaret Weir \& Theda Skocpol, "State Structures and the Possibilities for 'Keynesian' Responses to the Great Depression in Sweden, Britain, and the United States", in Peter Evans, Dietrich Rueschemeyer \& Theda Skocpol (eds.), Bringing the State Back In, Cambridge, Cambridge University Press, 1985, pp. 107-163; Daniel Capenter, The Forging of Bureaucratic Autonomy: Reputations, Networks, and Policy Innovation in Executive Agencies, 1862-1928, Princeton, Princeton University Press, 2001.

${ }^{35}$ Jos Raadschelders suma otras cuatro categorías: quienes realizan trabajo físico, el personal auxiliar que desarrolla actividades administrativas menores, el personal del sector salud y el del ámbito de la educación. Jos C.N. Raadschelders, Handbook of Administrative History, New Brunswick, Transaction, 1998, p. 140.

${ }^{36}$ Leonard White, The Jacksonians: A Study in Administrative History, 1829-1861, New York, Macmillan, 1954, p. 394.

${ }^{37}$ A.G.M Bekke, James Perry \& Theo A.J. Toonen, "Introduction. Conceptualizing Civil Service Systems", in Hans A.G.M Bekke, James Perry \& Theo A.J. Toonen (eds.), Civil Service Systems in Comparative Perspective, Bloomington, Indiana University Press, 1996, pp. 1-10.

${ }^{38}$ Jos C.N. Raadschelders, Theo A.J. Toonen \& Frits van der Meer, "Introduction. Civil Service Systems and the Challenges of the 21st Century”, in Raadschelders, Toonen \& Meer (eds.), The Civil Service... op. cit., pp. 1-13.

${ }^{39}$ Omar Guerrero, "Servicio civil de carrera en México. Origen y evolución", en Instituto Nacional de Administración Pública (eds.), Avances del México contemporáneo, 1955-2015, México, Instituto Nacional de Administración Pública, 2015, p. 26.

${ }^{40}$ Weber, op. cit., pp. 716-718.
} 
Jos Raadschelders y Eran Vigoda-Gadot, basados en Aris Van Braam, plantean que existen rasgos burocráticos propios en relación con el funcionario público. Estos son los siguientes: 1) el puesto es ocupado por un funcionario individual; 2) que es subordinado; 3) nombrado; 4) que tiene experticia; 5) se encuentra en un esquema contractual; 6) tiene una posición segura; 7) desarrolla esta función como su único trabajo; 8) se desempeña en un sistema de carrera; 9) recibe un sueldo y pensión en dinero; 10) es pagado de acuerdo a su jerarquía; 11) es promovido por antigüedad y 12) trabaja bajo un esquema de protección formal de su oficio ${ }^{41}$.

A partir de la historia europea, Jos Raadschelders y Mark Rutgers ofrecen un esquema de desarrollo del empleo público, que reconoce cinco etapas ${ }^{42}$. A través de ellas se aprecia el paso desde la herencia de empleos, en las fases iniciales, a un sistema basado en el mérito en su versión más avanzada ${ }^{43}$. En primer lugar, los empleados fueron concebidos como asistentes personales de los señores feudales. Sin embargo, a partir de los siglos XV y XVI, debido a la secularización del poder y la irrupción del Estado moderno, estos empleados se convirtieron servidores del Estado. Por efecto de la irrupción de nuevas preocupaciones, como las mercantiles, los empleados requirieron tener un mayor grado de especialización. Entre 1780 y 1880, surgió lo que Raadschelders y Rutgers definen como el servicio civil moderno. En este periodo el empleado ya no es responsable frente a la persona del gobernante sino ante una autoridad impersonal definida constitucionalmente ${ }^{44}$. Esto ocurre debido a que la administración deja de ser dependiente del gobernante de turno, respondiendo al gobierno y la ciudadanía, junto con entregar servicios ${ }^{45}$. Estos cambios son frutos de la separación entre las esferas pública y privada, la Iglesia y el Estado, la política y la administración. Ello llevó a la creación de una autoridad constitucional y la distinción entre el funcionario y la oficina, eliminándose, por ejemplo, los cargos hereditarios. A la vez, la acción se especializó a través de la departamentalización, dejando atrás los cuerpos colegiados de administración. Finalmente, los funcionarios comenzaron a ser bien remunerados a través de salarios y pensiones. La cuarta etapa es la del surgimiento del servicio civil como un sistema protegido. Desde mediados del siglo XIX, en Estados Unidos y Europa se comenzó a utilizar el concepto de servicio civil y se establecieron normas de protección para evitar despidos por razones políticas o religiosas. La última fase es la del servicio profesional. Raadschelders y Rutgers señalan que tras la Segunda Guerra Mundial aumentó el nivel de especialización, garantizándose a través de niveles de educación exigidos, exámenes y concursos de ingreso ${ }^{46}$.

Hasta el surgimiento del servicio civil moderno, lo que primó fue un sistema de personal basado en el patronazgo. En este esquema, el nombramiento, promoción, despido

${ }^{41}$ Jos C.N. Raadschelders \& Eran Vigoda-Gadot, Global Dimensions of Public Administration and Governance. A Comparative Voyage, New Jersey, Jossey-Bass, 2015.

42 Jos C.N. Raadschelders \& Mark Rutgers, "The Evolution of Civil Service Systems", in Bekke, Perry \& Toonen (eds.), Civil Service Systems..., op. cit., pp. 67-99.

${ }^{43}$ Jos C.N. Raadschelders, "Changing European Ideas about the Public Servant: A Theoretical and Methodological Framework for Why and How to Study This", in Fritz Sager \& Patrick Overeem (eds.), The European Public Servant: A Shared Administrative Identity?, Colchester, ECPR Press, 2015, pp. 15-34.

${ }^{44}$ Raadschelders \& Rutgers, op. cit.

${ }^{45}$ Raadschelders \& Vigoda-Gadot, op. cit.

${ }^{46}$ Raadschelders \& Rutgers, op. cit. 
y otras decisiones se toman en consideración de la militancia política del personal ${ }^{47}$. Los casos más reseñados en la literatura para describir el patronazgo son los de Gran Bretaña y Estados Unidos durante gran parte del siglo XIX. El llamado sistema de botín (spoil system) surgió en Estados Unidos en un contexto de ampliación democrática, a partir de 1829. El sistema se fundó en tres principios: los nombramientos se basaban en consideraciones políticas (en específico, lealtad y trabajos electorales previos del funcionario), los nombramientos estaban en manos del Congreso y se instauró la rotación de personal ${ }^{48}$. El sistema de botín fue definido en América Latina y España como empleomanía. Salvador Parrado la define como una situación en la que los partidarios están expectantes de recibir un empleo como recompensa por su dedicación a una causa política. Ello implica que la administración pública es patrimonio del gobierno ${ }^{49}$.

La transición hacia un servicio civil moderno se dio a través de una serie de medidas que se tomaron para instaurar exámenes de competencia para la contratación y promoción de los candidatos ${ }^{50}$. La transición no implica solo el establecimiento de leyes o comisiones en ese sentido, sino que requiere, además, un cambio de valores en la sociedad $^{51}$, en específico una reconceptualización sobre las características de la administración pública, que se aleje de la idea que ella es propiedad del gobierno de turno. En ese sentido, Bernard Silberman ha planteado que la profesionalización en la administración del Estado ocurre en contextos de alta competencia política. Ellos llevan a que la profesionalización sea deseable para reducir los niveles de incertidumbre respecto a las políticas públicas ${ }^{52}$.

En síntesis, un servicio civil moderno es un sistema que cuenta con normativas y prácticas administrativas que cautelan que los nombramientos sean hechos sobre la base del mérito, y que establecen garantías para los empleados, principalmente un esquema de salario y pensiones, estabilidad en el empleo y mecanismos de promoción que permiten materializar la idea de carrera administrativa de Max Weber. En las siguientes tres secciones se analiza la forma en que se hacía carrera en la Dirección de Contabilidad, el Tribunal de Cuentas e Impuestos Internos, a partir del análisis de la normativa y las prácticas administrativas durante cuarenta años.

47 Robert A. Cropf, American Public Administration: Public Service for the $21^{\text {st }}$ Century, New York, Routledge, 2016, p. 326.

${ }^{48}$ Ari Hoogenboom, Outlawing the Spoils: A History of the Civil Service Movement, 1865-1883, Urbana, The University of Illinois Press, 1961, pp. 2-4.

${ }^{49}$ Salvador Parrado, "The Development and Current Features of the Spanish Civil Service System", in Hans A.G.M. Bekke \& Frits van der Meer (eds.), Civil Service Systems in Western Europe, Northampton, Edward Elgar Publishing, 2000, pp. 247-274.

${ }^{50}$ Leonard White, The Republican Era: 1869-1901. A Study in Administrative History, New York, Macmillan, 1958, pp. 346-354; Edgar Norman Gladden, Una historia de la administración pública. Desde el siglo XI hasta nuestros días, México, Fondo de Cultura Económica, 1989, p. 364.

${ }^{51}$ Donald E. Klingner, "Patronage and Spoils", in Jack Rabin (ed.), Encyclopedia of Public Administration and Public Policy, Middletown, Marcel Dekker, 2003, pp. 880-884.

${ }^{52}$ Bernard Silberman, Cages of Reason: The Rise of the Rational State in France, Japan, the United States, and Great Britain, Chicago, The University of Chicago Press, 1993. 


\section{EL MARCO NORMATIVO:}

ESTRUCTURA Y JERARQUÍA, NOMBRAMIENTOS, REMUNERACIONES Y PENSIONES

\section{Estructura y jerarquía en las oficinas}

Hacia la década de 1880, gran parte de las oficinas públicas chilenas se encontraban muy reglamentadas, tanto en su estructura como en sus procesos ${ }^{53}$. La Dirección de Contabilidad y el Tribunal de Cuentas ${ }^{54}$ fueron organizados mediante leyes de los años 1883 y 1888, respectivamente. Desde ahí, hasta 1920, si bien fueron reformadas sus plantas, en 1914 y 1911 -y se discutieron posibles cambios a las oficinas de Hacienda en los años 1900, 1903, 1905, 1906 y $1918^{55}$ - no sufrieron alteraciones radicales en cuanto a los objetivos y funciones que debían realizar. Ello ocurrió en 1927, cuando ambos servicios se funden y dan origen a la Contraloría General de la República.

La ley del 24 de enero de 1883, que organizó la Dirección del Tesoro y la Dirección de Contabilidad, encargó a la segunda el manejo de la contabilidad de la Hacienda Pública, actuar como interventora de las operaciones de la tesorería y otras oficinas públicas que manejaban fondos fiscales y, además, preparar la recaudación de los impuestos públicos. Sobre la base de este mandato legal, la Dirección de Contabilidad tenía que realizar tareas que eran sensibles para el fisco y el mundo político, como formar cada año el presupuesto, hacer informes sobre las entradas y las deudas fiscales, y prescribir un sistema contable uniforme para las distintas oficinas públicas. La oficina contaba con un director, un subdirector, un cuerpo de inspectores fiscales y una sección encargada del crédito público ${ }^{56}$.

Por su parte, el Tribunal de Cuentas tenía a su cargo el examen y juzgamiento de las cuentas que debían rendir los empleados, establecimiento y personas que administraban, recaudaban o invertían fondos fiscales. La oficina estaba compuesta por dos secciones: una primera, que terminó dividiéndose en cinco distintas, encargada de examinar la veracidad, fidelidad y legalidad de las cuentas presentadas por los empleados o establecimientos a cargo de fondos fiscales, y una segunda, llamada Corte de Cuentas, en la que se realizaban los juicios de las cuentas que hubiesen sido reparadas por la sección

\footnotetext{
${ }^{53}$ Barría, "Rasgos burocráticos...", op. cit.

${ }^{54}$ El Tribunal de Cuentas se creó en 1767. Antes de esa fecha, el control de las finanzas públicas se realizó a través del tribunal existente en Lima. La primera reforma de este cuerpo se realiza en 1820, y en 1839 se dicta la ley que organizó el servicio bajo el nombre de Contaduría Mayor. López, op. cit., pp. 69-73. En 1855 se dicta una ley que estableció la planta del servicio, hasta su reforma en 1888.

${ }^{55}$ Referencias a momentos de discusión de reformas de estas oficinas se encuentran en Nota del presidente del Tribunal de Cuentas No 338 B, Santiago, 29 de mayo de 1900, en Archivo Nacional de la Administración (en adelante ARNAD), AMH, vol. 2984 "Tribunal de Cuentas 1898-1900"; Nota del presidente del Tribunal de Cuentas N³39, Santiago, 1 de junio de 1903, en ARNAD, AMH, vol. 3440 "Tribunal de Cuentas 1903-1904"; Nota del director de Contabilidad, sin número, Santiago, 19 de mayo de 1905, en ARNAD, AMH, vol. 3690 "Dirección de Contabilidad $19052^{\circ}$ semestre"; Nota del director de Contabilidad No 1217 , Santiago, 27 de noviembre de 1905, en ARNAD, AMH, vol. 3798 "Dirección de Contabilidad $19061^{\text {er }}$ semestre"; Nota del presidente del Tribunal de Cuentas N 448, Santiago, 20 de julio de 1918, en ARNAD, AMH, vol. 5041 "Tribunal de Cuentas 1918-22".

${ }^{56}$ Boletín de Leyes y Decretos del Gobierno (en adelante BDLG), Santiago, Imprenta Nacional, 1883, pp. 97 102.
} 
de examen. Esta Corte estaba compuesta por el Presidente, tres ministros, un fiscal y un relator-secretario. La oficina debía, además, tomar razón de las leyes, decretos, otras medidas gubernamentales y sentencias judiciales que se relacionaban con el fisco ${ }^{57}$.

En las décadas posteriores, ambas agencias públicas continuaron cumpliendo las funciones asignadas por las leyes, además de ser asesoras del ministerio en materias fiscales, y vieron aumentar sus responsabilidades, pues fueron receptoras de tareas estatales nuevas. Por ejemplo, la Dirección de Contabilidad debió iniciar el control sobre la administración de impuestos sobre los alcoholes ${ }^{58}$, junto con ejercer vigilancia sobre el mercado de seguros ${ }^{59}$. Por su parte, el Tribunal de Cuentas tomó a su cargo la inspección de las tesorerías de los municipios (1896) y de Ferrocarriles del Estado (1915). Además, por cumplir las funciones antes descritas, fueron especialmente sensibles ante cada aumento de gastos, funciones estatales o creación de agencias públicas, que se traducían en una mayor cantidad de fondos que registrar y juzgar.

En el caso de la Dirección de Impuestos Internos, fue creada en 1902 por la ley $\mathrm{N}^{\mathrm{o}}$ 1515 con el nombre de Administración del Impuesto sobre Alcoholes. Esta oficina, dependiente del Ministerio de Hacienda, fue organizada a través del decreto del 5 de julio de 1912, que la nombró como la Administración General de Impuestos y la ley № 3087 , que en 1916 modificó la ley $N^{o} 1515$ y comenzó a nombrar a la oficina como la Dirección de Impuestos Internos.

Los marcos normativos de las tres oficinas establecieron de forma clara la planta de cada una de ellas, indicando los puestos y su jerarquía. La planta de la Dirección de Contabilidad estaba compuesta por un director, que también actuaba como inspector de oficina; un subdirector; un secretario; un contador primero, que era el jefe de la Sección de Crédito Público; dos contadores primeros; tres contadores segundos; tres oficiales terceros; tres oficiales cuartos; seis oficiales quintos; un inspector de aduanas; seis inspectores y un portero ${ }^{60}$. La planta de la Contaduría Mayor, establecida en 1855, estaba compuesta por el Contador Mayor; cuatro contadores primeros; ocho contadores segundos; doce oficiales; un archivero primero; un archivero segundo; dos oficiales de pluma; un oficial de pluma; un oficial de fe pública; un amanuense para el contador y un portero ${ }^{61}$. En tanto, la planta que la ley de 1888 creó para el Tribunal de Cuentas fue la siguiente: el presidente de la Corte; tres ministros, un fiscal; un relator-secretario; cuatro jefes de sección; cuatro examinadores primeros; ocho examinadores segundos; ocho examinadores terceros; ocho examinadores cuartos; ocho examinadores quintos; cuatro oficiales primeros; cuatro oficiales segundos; cuatro oficiales terceros; un archivero pri-

${ }^{57} B D L G$, Santiago, Imprenta Nacional, 1888, pp. 174-179.

${ }^{58}$ En 1902 se creó este servicio de cobro de impuestos. El entonces director, J.C. Cuevas, solicitó empleados auxiliares para hacer frente al nuevo trabajo que ello demandaba para la Dirección. Nota del director de Contabilidad N ${ }^{\circ}$ 560, Santiago, 2 de junio de 1902, en ARNAD, AMH, vol. 3310 "Dirección de Contabilidad $1^{\circ}$ semestre".

${ }^{59}$ El servicio aparece por primera vez nombrado en 1913, estando a cargo del inspector de oficinas fiscales, Martín Figueroa. "Relación de trabajos i comisiones de los inspectores durante el año de 1913", sin número, Santiago, sin fecha, en ARNAD, AMH, vol. 4013 "Dirección de Contabilidad 1908-1914".

${ }^{60} B D L G$, Santiago, Imprenta Nacional, 1883, pp. 101-102.

${ }^{61} B D L G$, Santiago, Imprenta Nacional, 1855, pp. 334. 
mero; un archivero segundo; un portero primero; un portero segundo ${ }^{62}$. En el caso de la Dirección de Impuestos, la ley estableció una planta formada por un administrador, que cumplía la función de jefe de oficina; un químico; un secretario; un contador estadístico; un ayudante; un portero; doce inspectores y hasta veinticuatro subinspectores ${ }^{63}$.

\section{Nombramientos}

Julio Heise ha planteado que, hasta 1891, políticos y juristas pensaban que los servidores del Estado se regían por una idea de contrato con el Jefe de Estado, propia del Derecho Civil, en la cual el empleado público era mandatario de un mandante, el Presidente de la República. De esta manera, el último tenía la capacidad de suspender de sus funciones a los empleados, tal como los había puesto en ellos y en ningún caso existía una estructura burocrática ${ }^{64}$. A continuación, se muestra que esa afirmación no es totalmente cierta, como el mismo Heise apuntó.

La administración pública chilena decimonónica no contaba con una norma de carácter general respecto a cómo seleccionar sus empleados. Tras la Independencia, los nombramientos se realizaron a partir de la lealtad, y con posterioridad fueron apareciendo algunas normas específicas ${ }^{65}$. La ley del 7 de junio de 1884 , por ejemplo, estableció que los empleos en los que el Presidente de la República no requiriera la propuesta o el acuerdo de otro poder constitucional o corporación creada por ley, eran de su exclusiva confianza ${ }^{66}$. De esta manera, el Presidente de la República contaba con un amplio margen para actuar de modo discrecional y nombrar, si así lo quería, a gran parte de los empleados públicos.

No obstante, durante el siglo XIX fueron apareciendo algunos requisitos de ingreso. El decreto-ley que organizó los ministerios en 1837 combinó requisitos de estudios con otros sociales, principalmente la honorabilidad. En la reforma ministerial de 1887 al bachillerato en Humanidades se sumaron cursos universitarios específicos, dependiendo de la especificidad requerida por el puesto ${ }^{67}$. Hacia 1892, Domingo Amunátegui Rivera identificó varios servicios en los que se solicitaban conocimientos específicos para ocupar puestos administrativos, como la Dirección de Obras Públicas y Correos. Destacaba, además, que en el Registro Civil se realizaban concursos y que en el servicio de telégrafos se implementaron exámenes y un periodo de práctica de dos meses ${ }^{68}$.

En el caso de las leyes que organizaron la Dirección de Contabilidad, el Tribunal de Cuentas y la Dirección de Impuestos Internos no se determinaron requisitos de ingreso para los distintos puestos administrativos, pero sí se normó la forma en que debían rea-

\footnotetext{
${ }^{62} B D L G$, Santiago, Imprenta Nacional, 1888, pp. 175-176.

${ }^{63}$ Ley $\mathrm{N}^{\mathrm{o}} 1515$, disponible en www.leychile.cl/Navegar?idNorma=22709 [fecha de consulta: 28 de mayo de 2018].

${ }^{64}$ Heise, op. cit., p. 311.

${ }^{65}$ López, op. cit., p. 251.

${ }^{66} B D L G$, Santiago, Imprenta Nacional, 1884, pp. 679-680.

${ }^{67}$ Diego Barría, "Continuista o Rupturista, Radical o Sencillísima: La Reorganización de Ministerios de 1887 y su Discusión Político-Administrativa”, en Historia, vol. 41, № 1, Santiago, 2008, p. 9.

${ }^{68}$ Domingo Amunátegui Rivera, Algunas observaciones sobre la reorganización administrativa, Santiago, Imprenta Cervantes, 1892, p. 75.
} 
lizarse los nombramientos. En la Dirección de Contabilidad se estableció que el director, subdirector, inspectores y contadores primeros serían considerados empleados superiores, por lo que la designación dependería del Presidente de la República ${ }^{69}$. En el Tribunal de Cuentas el sistema era más complejo. El presidente de la Corte de Cuentas, sus ministros y fiscales serían seleccionados por el Presidente de la República a partir de una terna presentada por el Consejo de Estado. En el caso de los ministros, dichas ternas debían conformarse a partir del listado de fiscales entregados cada año por la Corte de Cuenta al Presidente de la República. En tanto, el relator-secretario, los jefes de sección, examinadores y archivadores debían ser nombrados por el Presidente de la República a partir de una terna propuesta por la Corte de Cuentas. El resto de los empleados eran nombrados por el presidente de la Corte ${ }^{70}$. En la Dirección de Impuestos Internos se estableció en 1902 que el administrador sería elegido por el Presidente de la República a partir de una terna presentada por el Consejo de Estado. Los inspectores y subinspectores debían ser contratados a través de concurso público, mientras que en el resto de los casos el nombramiento recaía en el Presidente de la República a partir de una terna entregada por el administrador ${ }^{71}$.

\section{Remuneraciones}

Durante el periodo estudiado, las remuneraciones de los empleados públicos eran fijadas por las leyes que creaban las oficinas públicas o por otras en que se modificaban las plantas funcionarias. En tanto, los empleados que no eran parte de la planta recibían remuneraciones establecidas por la ley de presupuesto del año en curso. Esta situación limitaba las posibilidades de reajustar los ingresos ante eventos como la inflación. No obstante, ello no significó la estagnación total de las remuneraciones. En las primeras dos décadas del siglo xx, estas fueron reajustadas en varias ocasiones, algunas veces al alza $^{72}$, debido a la inflación y en otras a la baja, a causa de los apuros fiscales ${ }^{73}$.

Se dictaron normas de carácter general respecto al derecho a jubilación y licencias. Desde 1820 se discutió la posibilidad de dar pensiones a quienes no pudieran continuar en sus funciones por imposibilidad física o moral, y se aprobaron normas en esa línea en 1827 y 1832. Esta última estableció dos causales: la primera, la imposibilidad antes mencionada; la segunda, requería cumplir sesenta y cinco años de edad, cuarenta años

${ }^{69} B D L G$, Santiago, Imprenta Nacional, 1883, p. 102.

${ }^{70} B D L G$, Santiago, Imprenta Nacional, 1888, p. 186.

${ }^{71}$ Ley $\mathrm{N}^{\mathrm{o}} 1515$, op. cit.

72 Por ejemplo, en 1906 se dictó una ley que ayudaba económicamente a los empleados públicos y a contrata que hubiesen sufrido daños por el terremoto del año: BDLG, Santiago, Imprenta Nacional, 1906, p. 1399. En 1907, se dictó la ley No 1929, sobre gratificación, que aumentaba los sueldos de los empleados -en distintas magnitudes, dependiendo de su nivel de ingreso- que no hubiesen recibido un aumento en el presupuesto del año: $B D L G$, Santiago, Imprenta Nacional, 1907, pp. 163-164.

${ }^{73}$ A través de la ley $\mathrm{N}^{\circ} 2987$, del 1 de marzo de 1915, se realizó un descuento del 15\% a sueldos, gratificaciones, asignaciones y pensiones fijadas por leyes permanentes con posterioridad al 1 de enero de $1910 \mathrm{o}$ aumentadas por leyes posteriores a la fecha. La reducción fue de un $10 \%$ para los que fueron fijados antes de esa fecha. Se exceptuaban los casos en que la ley de presupuestos del año o leyes posteriores al 1 de agosto de 1914 ya hubiesen realizado los descuentos: Ricardo Anguita, Leyes promulgadas en Chile desde 1810 al $1^{\circ}$ de junio de 1912, Santiago, Imprenta, Litografía y Encuadernación Barcelona, 1918, tomo Iv, p. 226. 
de servicio y la aprobación del gobierno ${ }^{74}$. Con posterioridad, a través de la ley del 10 de agosto de 1857 se determinó que podían recibir jubilación aquellos empleados con más de cuarenta años de servicios en la administración, que tuvieran sesenta y cinco años de edad o presentaran problemas de salud, y hubieran servido por más de diez años en la administración. El monto se fijaba a través de un cálculo en el que cada año de servicio sumaba, a la cifra final, un cuarentavo del sueldo recibido por el empleado (con posterioridad, leyes específicas cambiaron el valor). Las normativas que crearon la Dirección de Contabilidad y el Tribunal de Cuentas fijaron ese monto en un $75 \%$ de la remuneración ${ }^{75}$. En 1898 se dictó una nueva ley de jubilaciones, en la cual se estableció que aquellos funcionarios con sesenta y cinco años de edad y cuarenta de servicio, podían jubilar sin necesidad de demostrar problemas de salud o impedimento físico o moral $^{76}$. Por su parte, una ley del 10 de septiembre de 1869 , reconoció a los empleados propietarios el derecho a un mes de licencia al año (vacaciones) y a gozar de hasta ocho meses de licencia por salud -en los dos primeros se pagaba el 100\% del sueldo y en los posteriores dos un $50 \%$ y en el resto el $0 \%-$ y otros dos por asuntos particulares, sin derecho a sueldo ${ }^{77}$. En 1898, mediante la ley $\mathrm{N}^{0} 1041$, los plazos fueron reducidos a tres meses por motivos de salud, un mes por asuntos particulares y quince días de vacaciones para los auxiliares sin derecho hasta ese momento a dicho feriado ${ }^{78}$.

En síntesis, durante el periodo existían algunos criterios propios de la burocracia, como la existencia de oficinas reglamentadas y jerárquicas. A la vez, la función administrativa fue considerada como una cuestión que requería especialización. Igualmente, se establecieron sistemas de pagos y pensiones que permitían desarrollar una carrera administrativa. Sin embargo, no habían mecanismos formales de aseguramiento de carrera, como la estabilidad en el empleo. En las siguientes secciones se muestra que, aunque no existía una norma que asegurara la estabilidad en el empleo, una serie de prácticas administrativas sí lo hacían, permitiendo a los funcionarios desarrollar carreras administrativas largas.

\section{LA DURACIÓN DE LAS CARRERAS ADMINISTRATIVAS}

¿Había carrera administrativa en Chile a fines del siglo XIX y antes de la década de 1920? Esta pregunta puede ser abordada a través del análisis del tiempo que los empleados permanecían en la administración. Aunque no existe información sistematizada ni estadísticas agregadas, sí es posible reconstruir carreras de diversos funcionarios, para tener una impresión general. A continuación, se presentan datos respecto al promedio de años en servicio en la administración pública de los empleados públicos en el Tribunal de Cuentas (no existen datos para todos los empleados de la Dirección de Contabilidad).

\footnotetext{
${ }^{74}$ López, op. cit., pp. 285-286.

${ }^{75} B D L G$, Santiago, Imprenta Nacional, 1857, pp. 219-222.

${ }^{76}$ Ley $\mathrm{N}^{\mathrm{o}} 1146$, disponible en www.leychile.cl/Navegar?idNorma=22430 [fecha de consulta: 28 de mayo de 2018].

${ }^{77} B D L G$, Santiago, Imprenta Nacional, 1869, pp. 304-305.

${ }^{78} B D L G$, Santiago, Imprenta Nacional, 1898, pp. 492-524.
} 
Estos promedios fueron construidos a partir de informes del Tribunal de Cuentas en que contabilizaban los años que habían transcurrido desde que cada uno de sus empleados en servicio había recibido su primer nombramiento en la administración pública ${ }^{79}$.

El promedio de años de servicio de la planta de empleados del Tribunal de Cuentas fue aumentando con el transcurso del tiempo. La Contaduría Mayor exhibía, en 1884, un promedio de 8,2 años de servicio por empleado. Solo el $26,60 \%$ de la planta contaba con más de diez años. En ese grupo destacaban empleados con veintitrés, veintisiete y treinta y ocho años en la administración pública. Sin embargo, una gran parte, el 46,60\% tenía cuatro años o menos ${ }^{80}$.

En 1887, se aprecia un pequeño aumento del promedio de años de servicio, alcanzando los 8,5 años. Esto se explica tanto por el aumento del porcentaje de la planta con más de diez años de servicio (31\%) como por la disminución de quienes tenían cuatro años o menos $(39,60 \%)^{81}$. Muy probablemente, el promedio debió reducirse tras la guerra civil de 1891. A inicios de 1891, en el Tribunal de Cuentas se contrataron dieciocho empleados para reemplazar a personas que sirvieron hasta el 31 de diciembre de 1890. Dos ingresaron en febrero, siete en junio y nueve en julio. Todos ellos fueron despedidos el 28 de agosto, fecha en la que volvieron los antiguos empleados separados durante el periodo de la guerra $^{82}$. Con la derrota de José Manuel Balmaceda, diez empleados, que servían con anterioridad al 31 de diciembre de 1890, fueron separados el mismo 28 de agosto de $1891^{83}$.

En 1904, el promedio de tiempo de servicio se redujo, alcanzando los ocho años. Si bien el porcentaje de la planta de empleados con diez o más años de servicio aumentó, alcanzando el 34,50\% del total, el grupo de quienes tenían cuatro o menos años también creció, representando más de la mitad de los empleados (53,50\%). En parte, ello se puede entender porque el comienzo de la década de 1900 marca una coyuntura de contratación de empleados nuevos. En 1896 comenzó a funcionar la sección de cuentas municipales, que debió contratar a un total de trece empleados, la mayoría de ellos sin experiencia previa. En 1904, la sección estaba compuesta por empleados nombrados con posterioridad a 1900. Ello hace que esta sección, por sí sola, reduzca el promedio de años de servicios en un año ${ }^{84}$.

${ }^{79}$ Si bien durante la década de 1880 la documentación del Tribunal de Cuentas es bastante completa en materia de despidos o renuncias, en las décadas posteriores la información sobre el particular es escasa, razón por la cual no se ha podido realizar el ejercicio de determinación de cuándo las carreras finalizaron. Además, aun cuando ello hubiese sido posible, no hay forma de seguir una eventual continuación de la carrera del empleado en otra oficina.

${ }^{80}$ Cálculos propios sobre la base de "Nómina de los empleados de la Cont. Mayor con especificación de la fecha de sus primeros i últimos nombramientos i del tiempo que han servido hasta el 19 de Abril de 1884", Santiago, sin fecha, en ANH, AMH, vol. 1421 "Contaduría Mayor 1884".

${ }^{81}$ Cálculos propios a partir de Contaduría Mayor, Memoria de la Contaduría Mayor, Santiago, Imprenta Nacional, 1887, pp. 62-63.

82 “Empleados nombrados en 1891 para servir en el Tribunal de Cuentas i que quedaron cesantes el 28 de agosto del mismo año al tomar posesión de sus puestos los que servían dichos cargos el 31 de diciembre de 1890", Santiago, sin fecha, en ANH, AMH, vol. 2634 "Tribunal de Cuentas 1895-1896".

${ }^{83}$ En 1896 se dictó una ley reparadora para empleados que fueron despedidos de las oficinas tras la caída de José Manuel Balmaceda. En ella se les dio una gratificación y se les reconoció el derecho a tener una jubilación. BDLG, Santiago, Imprenta Nacional, 1896, pp. 671-672.

${ }^{84}$ Cálculos propios sobre la base de "Nómina de los empleados del Tribunal de Cuentas con especificación del primer i último nombramiento que han obtenido en la oficina", sin número, Santiago, sin fecha, en ARNAD, AMH, vol. 3440 "Tribunal de Cuentas 1903-1904". 
Más allá de esta coyuntura, las cifras de 1904 ya muestran algo que se verá con mayor claridad a fines del periodo de estudio: la proporción de empleados con más de diez años aumentaba constantemente. En 1919, el Tribunal de Cuentas alcanzaba un promedio de años de servicio de 11,5. Quienes tenían más de diez años de servicios constituían casi la mitad de la planta $(49,40 \%)$ mientras que quienes tenían cuatro años o menos representaban un $37,60 \%$ del tota ${ }^{85}$.

Si bien para la Dirección de Contabilidad no es posible construir estos datos, pues no existen listados de empleados como los disponibles para el Tribunal de Cuentas, se sabe que los empleados con cargos altos tenían una antigüedad considerable. En algún momento no especificado en la fuente, pero que debió ser entre 1914 y 1916, la Dirección de Contabilidad elaboró un informe en el que se contaban los años de servicio del personal superior de la oficina ${ }^{86}$. El promedio era de 18,6. Si se excluye de esa lista a un empleado, al que solo se le conocía un año de servicio y se ignoraba el resto de su carrera, el promedio llega a los veinte años de actividad previa. El empleado que más años de servicio tenía, alcanzaba los treinta y $\operatorname{dos}^{87}$.

Estos datos permiten afirmar que existió un grupo de personas -en constante crecimiento- que desarrolló parte importante, sino toda su vida laboral, en la administración pública. Ejemplo de esto es la solicitud de los empleados del Taller de Papel Moneda que funcionaba en la Dirección de Contabilidad, al correr el riesgo de quedarse sin trabajo por la externalización del servicio. En esa carta solicitaron al ministro de Hacienda que no los dejara sin trabajo, pues habían hecho:

"[...] de este empleo nuestra profesion habitual, la base de nuestros medios de subsistencia, i toda la esperanza del porvenir, puesto que trabajando durante largo tiempo en él, es casi nuestro unico conocimiento i la sola seguridad para el futuro" ${ }^{\circ 8}$.

Tomás Middleton, por ejemplo, trabajó por casi treinta y dos años en oficinas públicas. En febrero de 1855 ingresó a la Oficina de Estadística, como oficial auxiliar, puesto que sirvió por un mes. Volvió a la administración, en 1857, esta vez como oficial de número de la Contaduría Mayor. Sirvió por doce años en ese puesto, hasta que, en 1869, fue ascendido a Oficial de Fe Pública. En 1870, fue nombrado contador $2^{\circ}$ interino y un año después obtuvo la propiedad del puesto. En 1881, ascendió a contador $1^{\circ}$ y, en 1888, obtuvo su último ascenso, siendo nombrado jefe de sección del Tribunal de Cuentas. Sirvió, además, comisiones en 1869, 1871 y 1872 para formar patentes en el Departamento de Santiago; en 1871, fue enviado a la administración del estanco de Vi-

\footnotetext{
${ }^{85}$ Lista de empleados del Tribunal de Cuentas, anexo de Nota del presidente del Tribunal de Cuentas $\mathrm{N}^{\circ} 323$, Santiago, 23 de junio de 1919, en ARNAD, AMH, vol. 5041 “Tribunal de Cuentas 1918-1922”.

${ }^{86}$ El personal superior de la Dirección de Contabilidad, nombrado directamente por el Presidente de la República, estaba compuesto por el director, subdirector, los inspectores y los contadores $1^{\circ}$. BDLG, Santiago, Imprenta Nacional, 1883, p. 102.

87 “Años de Servicios del Personal Superior de la Direccion Jeneral de Contabilidad”, Santiago, sin fecha, en ARNAD, AMH, vol. 4685 "Dirección de Contabilidad 1914-1916".

${ }^{88}$ Solicitud de los empleados del Taller de Papel Moneda, sin número, Santiago, 9 de junio de 1884, en ANH, AMH, vol. 1477 "Solicitudes empleados 1884".
} 
chuquén; un año más tarde representó al fisco frente al Juzgado de Comercio de Santiago; en 1879, administró temporalmente el estanco del sur de Santiago, por renuncia del anterior administrador, José Mateo Fabres, y reemplazó al contador mayor, José Santos Lira, tras la renuncia de este en $1884^{89}$.

Otro empleado con una larga estadía fue Antonio Jara. Ingresó a la Contaduría Mayor en 1861, como oficial auxiliar al servicio y, tras dos años, logró obtener el puesto de oficial en propiedad, en el que se desempeñó hasta 1871, año en el que fue nombrado contador $2^{\circ}$. En 1882, ascendió a contador $1^{\circ}$. En 1888, obtuvo el puesto de jefe de sección auxiliar $^{90}$. En su calidad de jefe continuó por un largo tiempo, pues, hacia 1899, seguía apareciendo en la documentación del Tribunal de Cuentas en esa calidad ${ }^{91}$. Si bien resulta incierta la fecha de fin de su carrera, se sabe que, al menos, estuvo en la oficina por un periodo de treinta y ocho años.

Una carrera similar a las anteriores es la de Manuel Olivos. Fue nombrado, en marzo de 1882, oficial $4^{\circ}$ de la Factoría General del Estanco y, en 1884, ingresó como oficial de pluma a la Dirección de Contabilidad. Por los siguientes treinta y cuatro años, desarrolló su carrera en ese servicio, hasta solicitar la jubilación, en 1918. En 1885, consiguió el puesto de oficial $5^{\circ} \mathrm{y}$, en 1887 , el de oficial $4^{\circ}$. Un año más tarde fue nombrado contador y, en 1889, obtuvo un puesto por la misma función, pero con más sueldo. En 1892 , fue nombrado contador $2^{\circ}$ y, en 1896 , alcanzó la categoría de $1^{\circ}$. En 1911 , lo designaron jefe de sección, cargo que ocupó hasta 1918, cuando se retiró a causa de una enfermedad. Murió en diciembre de ese año, a tan solo dos meses de haber solicitado su jubilación ${ }^{92}$.

En la Dirección General de Impuestos Internos también se conformó un grupo de funcionarios que desarrollaron carreras administrativas largas. Un reporte, sin fecha, pero que se refiere hasta el año 1921, resume las trayectorias de quienes, hasta ese momento, ocupaban las cinco jefaturas de sección. Luis Arístegui, jefe de la Sección de Tabacos, ingresó en 1902 a la oficina como subinspector de alcoholes. En 1910 fue promovido a inspector de plantas de tabacos, y luego jefe de la sección en 1913. Osvaldo Robles, jefe de la Sección de Vinos, también ingresó en 1902 como subinspector de alcoholes. En 1910 ocupó el puesto de inspector de alcoholes. Ocupó el puesto de visitador desde 1913 y en 1916 alcanzó la jefatura de sección. El jefe de la Sección de Alcoholes, Juan de Dios Castro registraba fecha de ingreso en 1902, como subinspector de alcoholes. Desde 1909 fue inspector y obtuvo el puesto de jefe de sección en 1913. Víctor Zañartu, jefe de la Sección de Timbres, llegó a la oficina en 1910 como inspector interino de tabacos. En 1911 asumió ese puesto en propiedad. En 1913 fue nombrado

89 "Hoja de servicios de don Tomas Middleton", documento anexo a nota del presidente del Tribunal de Cuentas N 448, Santiago, 25 de mayo de 1889, en ANH, AMH, vol. 2356 “Tribunal de Cuentas 1892-1893”.

${ }^{90}$ Nota del contador mayor, sin número, Santiago, sin fecha, en ANH, AMH, vol. 1601 "Contaduría Mayor 1886-1887'".

${ }^{91}$ Nota del presidente del Tribunal de Cuentas No 338 B, Santiago, 29 de mayo 1900, en ANH, AMH, vol. 2984 "Tribunal de Cuentas 1898-1900".

${ }_{92}$ Nota del director de Contabilidad No 1384, Santiago, 7 de octubre de 1918, en ARNAD, AMH, vol. 4202 "Dirección de Contabilidad 1910-1918” y "Hoja de Servicios del Jefe de Seccion Don Manuel L. Olivos", en el mismo volumen. 
visitador. En 1921 alcanzó el puesto de jefe de sección ${ }^{93}$. Otro caso es el de Romualdo Ravanal. Entre 1881 y 1891 fue gobernador en diversas localidades: Combarbalá (1886), Vallenar (1886-1890), Constitución (1890-1891), Puchacay (1894-1896), Collipulli (1901). En 1893 trabajó nueve meses como administrador interino de la Aduana de Junin. En 1902 ingresó a la Dirección de Impuestos Internos como oficial 1². Ocupó este puesto hasta 1912. Entre 1912 y 1914 fue contador $2^{\circ}$. Fue contador $1^{\circ}$ entre 1914 y 1918, hasta que en 1919 solicitó su jubilación por problemas de salud ${ }^{94}$.

Un rasgo característico de estas carreras es que los empleados, junto con mantenerse en una oficina por un importante periodo, se desempeñaron -a través de comisiones- en otras agencias públicas pertenecientes al ramo de Hacienda. Esta situación, quizá, se dio porque estas personas tenían los conocimientos requeridos -principalmente contablespara desempeñarse de buena forma en ese tipo de oficinas. Además, llama la atención que durante el tiempo que sirvieron en la administración, estos empleados fueron logrando ascensos. Es decir, hicieron sus carreras en la administración.

\section{MeCANismos DE ASCENSO}

La constatación de la duración de las carreras dificulta la aceptación de la tesis de la empleomanía. Quienes acusaban su existencia suponían que el Presidente de la República era quien hacía los nombramientos administrativos a su antojo. Sin embargo, a pesar de que tenía un importante espacio de maniobra para hacerlo, gracias a la ya mencionada ley del 7 de junio de 1884, no era el único actor a cargo de los nombramientos. En la práctica, quien nombraba a los empleados era el jefe de la oficina. El procedimiento "tipo" era el siguiente: se generaba la necesidad de contratar uno o más empleados -por una renuncia, un reemplazo o la autorización para contratar auxiliares o supernumerarios- y el jefe de oficina enviaba una propuesta al Ministro. En ella se especificaba el elegido o se presentaba una terna, en la que se establecía el orden de prioridad. Para el caso del Tribunal de Cuentas y la Dirección de Contabilidad, salvo contadas excepciones, el ministro de turno no hacía más que ratificar la selección del jefe de oficina ${ }^{95}$. En el caso de la Dirección de Impuestos Internos el jefe de oficina proponía ternas para los nombramientos. Generalmente, los que ocupaban el primer lugar en ellas eran nombrados por el ministro de Hacienda ${ }^{96}$. Esto es interesante, pues los administradores de la

93 "Cuadro que manifiesta las fechas en que los Jefes de Sección ingresaron al servicio con especificación de los ascensos y fechas respectivas", sin número, sin fecha, sin ciudad, en ARNAD, AMH, vol. 5186 "Dirección de Impuestos Internos 1920-1924".

${ }^{94}$ Nota del Tribunal de Cuentas $\mathrm{N}^{\circ}$ 130, Santiago, 30 de octubre de 1919, en ARNAD, AMH, vol. 4790 "Dirección de Impuestos Internos 1916-1919".

${ }^{95}$ De los archivos consultados, solo existe un nombramiento en el que el Ministro no ratifica la decisión del jefe de oficina. Nota del director de Contabilidad $N^{\circ} 1382$, Santiago, 2 de octubre, en ANH, AMH, vol. 1604 "Dirección de Contabilidad 1886". La rectificación de la propuesta se encuentra en el mismo volumen. Véase nota del director de Contabilidad $N^{\circ} 1596$, Santiago, 13 de noviembre y decreto del Ministerio de Hacienda $\mathrm{N}^{\circ} 2688$, Santiago, 30 de noviembre.

${ }^{96}$ Nota del Director de Impuestos Internos $N^{\circ} 151$, Santiago, 9 de enero de 1914 y decreto del Ministerio de Hacienda sin número, sin día, enero de 1913, en ARNAD, AMH, vol. 4627 "Dirección de Impuestos In- 
Dirección de Impuestos Internos solían preparar ternas en las que el primer lugar lo ocupaba quien ellos consideraban la persona que debía ocupar el cargo. Ello, a pesar que el artículo 128 de la ley $\mathrm{N}^{\circ} 1515$ establecía que las ternas debían ser presentadas por orden alfabético.

Las propuestas de nombramiento solo hacían una recomendación de personas, por lo que no es posible rastrear la forma mediante la cual se seleccionaba a quienes ingresaban por primera vez a las oficinas. Debido al escaso uso de sistemas formales de selección, como los concursos ${ }^{97}$ fijados por el decreto de Hacienda de octubre de 1886, lo más probable es que este proceso se realizara fuera de la oficina, tal vez en el ámbito de las relaciones sociales de los jefes de oficina. Lamentablemente, la documentación de la Dirección de Contabilidad y el Tribunal de Cuentas da pocas luces de esa dimensión de la vida de los empleados.

Sin embargo, se puede afirmar, de modo tentativo, que familias influyentes podían colocar a sus miembros en puestos administrativos. El ejemplo más claro es el de los Fabres. Mateo Fabres desarrolló una importante carrera en las oficinas de Hacienda. En 1879 aparece como administrador del estanco del sur de Santiago ${ }^{98}$, para después ser director de la Dirección de Contabilidad, contador mayor y presidente del Tribunal de Cuentas, durante la década de 1880. El paso de Mateo por estas oficinas fue fructífero para quienes ostentaban el apellido, toda vez que durante su estancia, Joaquín ${ }^{99}$, Miguel $^{100}$ y Horacio $^{101}$ Fabres encontraron ubicaciones en la Dirección de Contabilidad o la Contaduría Mayor. Otro ejemplo del peso de las familias para realizar nombramientos lo da la renuncia, en 1886, del oficial $5^{\circ}$ de la Dirección de Contabilidad, Santiago Montt Vergara y Camilo Montt Vergara fue su reemplazante ${ }^{102}$.

ternos 1914-1922"; Nota del Director de Impuestos Internos № 3755, Santiago, 5 de julio de 1916 y decreto del Ministerio de Hacienda $\mathrm{N}^{\circ}$ 1431, 13 de julio de 1915, en ARNAD, AMH, vol. 4672 "Dirección de Impuestos Internos 1915"; Nota del Director de Impuestos Internos N² 2846, Santiago, 16 de marzo de 1917 y decreto del Ministerio de Hacienda $N^{\circ}$ 606, Santiago, 23 de marzo de 1917, en ARNAD, AMH, vol. 4817 "Decretos Orijinales 600-699 1917".

${ }^{97}$ Al parecer, el uso de los exámenes para nombrar empleados fue utilizado en las oficinas de Hacienda. Junto al decreto de octubre de 1886, se fue introduciendo en la legislación -por ejemplo, en la ley que creó el Tribunal de Cuentas- este requisito para nombrar empleados. Su uso puede ser visto en diversos nombramientos realizados en la Dirección de Contabilidad y el Tribunal de Cuentas. Véase, decreto del Ministerio de Hacienda $N^{\circ}$ 2984, Santiago, 31 de diciembre de 1886, en ANH, AMH, vol. 1602 "Dirección de Contabilidad 1886 enero"; Nota del presidente del Tribunal de Cuentas $N^{\circ} 1551$, Santiago, 26 julio de 1889, en ANH, AMH, vol. 1978 "Tribunal de Cuentas 1889" y Nota del presidente del Tribunal de Cuentas No 3299 , Santiago, 31 de diciembre de 1889, en ANH, AMH, vol. 2102 "Tribunal de Cuentas 1890".

98 "Hoja de servicios de don Tomas Middleton", documento anexo a Nota del presidente del Tribunal de Cuentas N 448, Santiago, 25 de mayo de 1889, en ANH, AMH, vol. 2356 "Tribunal de Cuentas 1892-1893".

${ }_{99}$ Nota del director de Contabilidad $N^{\circ}$ 269, Santiago, 3 de abril de 1883, en ANH, AMH, vol. 1305 "Contabilidad Jeneral 18831 ".

${ }^{100}$ Nota del director de Contabilidad N ${ }^{\circ}$ 2382, Santiago, 18 de diciembre de 1883, en ANH, AMH, vol. 1304 “Contabilidad Jeneral 1883 2".

${ }^{101}$ Nota del contador mayor, sin número, Santiago, 25 de febrero de 1886, en ANH, AMH, vol. 1601 "Contaduría Mayor 1886-1887".

${ }^{102}$ Alberto Smith, al menos en dos ocasiones, nombró en puestos a personas que servían en la Dirección de Contabilidad bajo esa modalidad. En 1886 reemplazó a un empleado con licencia por una persona que servía a mérito y en otra favoreció a un "meritorio" con un puesto de oficial $5^{\circ}$ auxiliar. Nota del director de Contabilidad N 1008, Santiago, 3 de agosto de 1886, en ANH, AMH, vol. 1604 "Dirección de Contabilidad 
Otra vía de ingreso a las oficinas era la realización de reemplazos temporales de empleados ausentes o a través del ingreso ad honorem. Durante los primeros años de la vida independiente de Chile, esta modalidad tuvo un uso corriente en la administración pública. Desde la década de 1840 perdió importancia, pues la mejor condición económica del país permitió pagar remuneraciones ${ }^{103}$. A pesar de ser una forma contraria a cualquier criterio de burocratización, incluso en la década de 1880 iniciar la estadía en la administración a través de una labor "a mérito" significaba una posibilidad cierta de lograr un nombramiento, como reemplazante temporal o definitivo de un empleado ${ }^{104}$.

Un rasgo característico de las oficinas públicas de la época fue la existencia de una concepción jerárquica de la organización. La estructura de las plantas funcionarias estaba pensada verticalmente. Muestra de ello es que varios puestos, como el de oficial o contador, estaban ordenados desde el de mayor jerarquía $\left(1^{\circ}\right)$ hasta el último (n). Esta estructuración no implicaba solo una diferenciación en las remuneraciones pagadas, sino que, también, determinaba el lugar del empleado dentro de la jerarquía de la oficina. A la hora de hacer nombramientos, en la Dirección de Contabilidad y el Tribunal de Cuentas se promovía a los empleados que ocupaban el puesto inmediatamente inferior al vacante ${ }^{105}$. Por ejemplo, en una propuesta de ascensos realizada en la Dirección de Impuestos Internos, el jefe de oficina informó al ministro de Hacienda que su propuesta se basaba en orden de antigüedad ${ }^{106}$. Este procedimiento era coherente con un estado de ánimo en el mundo político, al menos presente en la década de 1880, que solicitaba que se establecieran mecanismos para el desarrollo de carreras dentro de la administración pública $^{107}$. El respeto de la jerarquía, aseguraba esta posibilidad. Así, un empleado que se quedaba por varios años en una oficina pública tenía la opción de ir ascendiendo en la planta hasta, quizá, llegar a ser jefe de oficina. Raimundo del Río es un ejemplo de lo planteado. Ingresó a la Contaduría Mayor, en 1879, en calidad de auxiliar. En marzo de 1880 fue nombrado oficial auxiliar y, en noviembre, en calidad de propietario. En 1886 fue amanuense del contador mayor y, en enero de 1888, secretario del nuevo Tribunal

1886" y Nota del director de Contabilidad N 443, Santiago, 8 de abril 1886, en ANH, AMH, vol. 1606 "Dirección de Contabilidad 1886".

${ }^{103}$ López, op. cit., pp. 207-209.

${ }^{104}$ Nota del director de Contabilidad No 852, Santiago, 12 de septiembre de 1890, en ANH, AMH, vol. 2103 "Dirección de Contabilidad 1890".

${ }^{105}$ Algunos nombramientos con las características mencionadas se encuentran en Nota del director de Contabilidad No 1151, Santiago, 7 de abril de 1884, en ANH, AMH, vol. 1423 "Contabilidad General 1884 2"; Nota del director de Contabilidad N 4112, Santiago, sin fecha, en ANH, AMH, vol. 1424 "Dirección de Contabilidad 1884 3"; Nota del contador mayor No 101, Santiago, 13 de enero de 1885, en ANH, AMH, vol. 1519 "Contaduría Mayor 1885"; Notas del presidente del Tribunal de Cuentas $\mathrm{N}^{\circ} 765$ y 1551, Santiago, 24 de abril y 26 de julio de 1889, ANH, AMH, vol. 1978 "Tribunal de Cuentas 1889"; Notas del presidente del Tribunal de Cuentas N 928 y 2917, Santiago, 9 de abril y 22 de agosto de 1890, en ANH, AMH, vol. 2102 "Tribunal de Cuentas 1890" y Nota director de Contabilidad $N^{\circ} 1283$, Santiago, 26 de octubre de 1893, en ANH, AMH, vol. 2454 "Dirección de Contabilidad 1893". Esta, es solo una minúscula muestra en relación con la cantidad de documentos de este tipo existentes tanto en el AMH del ANH y el ARNAD.

${ }^{106}$ Nota del Director de Impuestos Internos $\mathrm{N}^{\circ}$ 151, Santiago, 9 de enero de 1914, en ARNAD, AMH, vol. 4627 "Dirección de Impuestos Internos 1914-1922".

${ }^{107}$ Diego Barría, "En busca del mérito: la discusión académica en torno a los empleados públicos en Chile, 1884-1920”, en Estudos Ibero-Americanos, vol. 35, № 2, Porto Alegre, 2009, pp. 148-165. 
de Cuentas. Para mayo de ese año ya era examinador $1^{\circ}$ y en 1892 jefe de sección. Si bien no es clara la fecha de un ascenso nuevo, hacia 1900 aparece como ministro a cargo de un Juzgado de Cuentas y, en 1903 fue el reemplazante del presidente del Tribunal de Cuentas, Carlos Varas. La carrera de Del Río en el Tribunal de Cuentas finaliza en $1905^{108}$. En un periodo de veinticuatro años, logró pasar desde empleado auxiliar a jefe de oficina.

En la Dirección de Contabilidad se encuentra el caso de Alejandro Delgado. Ingresó al servicio como contador auxiliar, el año 1886. Un año después fue designado oficial $3^{\circ} \mathrm{y}$, a fines del mismo, como contador por $\$ 1500$ anuales. Su ascenso continuó durante los años posteriores y, en 1893, incluso, ejerció como subdirector interino y quedó, por un tiempo, a cargo de la oficina, en reemplazo del director, Alberto Smith. En 1905 fue nombrado director de la Dirección de Contabilidad, puesto que ejerció hasta, aproximadamente, $1916^{109}$. Tras diecinueve años, logró ser jefe de la oficina y ocupó ese puesto por casi once años.

Los empleados auxiliares, es decir, aquellas personas que ocupaban un puesto creado a través de la ley de presupuestos, tenían la misma opción. En la medida que iban quedando puestos vacantes, los empleados de planta iban ascendiendo y el último puesto quedaba libre. Era común que ese lugar fuese llenado con un empleado auxiliar. De esta forma, en la medida en que se mantuvieran en la oficina, los empleados tenían opciones de poder desarrollar sus carreras administrativas. Los mismos Raimundo del Río y Alejandro Delgado ingresaron como empleados auxiliares y, en breve tiempo, fueron logrando puestos en propiedad.

En la Dirección de Impuestos Internos, como se mostró con anterioridad, se usaron desde 1902 los concursos de competencia para nombrar a los inspectores y subinspectores. En los archivos de la Administración existen papeles asociados a estos exámenes. Ellos consideraban tres elementos: conocimientos administrativos generales y sobre los impuestos a los alcoholes, conocimientos de contabilidad y conocimientos técnicos. Estos concursos eran masivos. Por ejemplo, en uno realizado en 1917 participaron 165 as-

108 "Hoja de servicios de don José Raimundo del Río hasta el 31 de diciembre de 1889", Santiago, sin fecha, en ANH, AMH, vol. 1601 "Contaduría Mayor 1886-1887"; Nota del presidente del Tribunal de Cuentas, sin número, Santiago, sin fecha, en ANH, AMH, vol. 2356 "Tribunal de Cuentas 1892-1893"; Acta de visita 5 de enero de 1901, Santiago, en ARNAD, AMH, vol. 3186 “Tribunal de Cuentas 1901” y Nota del presidente del Tribunal de Cuentas N 183 B, Santiago, 30 de abril de 1903, en ARNAD, AMH, vol. 3439 "Tribunal de Cuentas 1903".

${ }^{109}$ Sobre los distintos ascensos de Alejandro Delgado, véase, Nota del director de Contabilidad No 1586 , Santiago, 10 de noviembre de 1886, en ANH, AMH, vol. 1604 "Dirección de Contabilidad 1886"; Nota del director de Contabilidad No 1439, Santiago, 16 de agosto de 1887, en ANH, AMH, vol. 1704 "Dirección de Contabilidad 1887"; Nota del director de Contabilidad No 2164, Santiago, 23 de diciembre de 1887, en ANH, AMH, vol. 1828 "Dirección de Contabilidad 1888"; Nota del director de Contabilidad N 189, Santiago, 23 de febrero de 1889, en ANH, AMH, vol. 1979 "Dirección de Contabilidad $18891^{\text {er }}$ trimestre"; Nota del director de Contabilidad No 245, Santiago, 25 de febrero de 1893, en ANH, AMH, vol. 2454 "Dirección de Contabilidad 1893" y ARNAD, AMH, vol. 3689 "Dirección de Contabilidad $19051^{\text {er }}$ semestre". En este volumen, Alejandro Delgado firma como director con posterioridad al 1 de mayo. Su reemplazante firma en propiedad ya el 11 de septiembre de 1916. Nota del director de Contabilidad No 1453, Santiago, 11 de septiembre de 1916, en ARNAD, AMH, vol. 4685 "Dirección de Contabilidad 1914-1916". 
pirantes ${ }^{110}$. Al hacer propuestas de nombramiento para estos cargos, el jefe de la oficina sugería al ministro de Hacienda una terna, ordenando a los postulantes de acuerdo con el puntaje obtenido ${ }^{111}$.

En resumen, las personas que trabajaban en la oficina pública tenían una posibilidad cierta de desarrollo profesional, en puestos que eran atractivos, tanto por las proyecciones que prometían como por los beneficios asociados (feriados y pensiones, por ejemplo) que traía trabajar para el Estado.

\section{CONCLUSIONES}

Tanto contemporáneos como diversos historiadores han planteado que en la llamada época parlamentaria, Chile vivió bajo los influjos de la empleomanía ${ }^{112}$. En este artículo se ha evidenciado que estas afirmaciones requieren ser revisadas en profundidad. Si bien se mostró que en algunas oficinas hubo un grupo importante de funcionarios con cuatro o menos años de servicio, lo que podría dar pie a plantear la existencia de una rotación asociada al ciclo político, el porcentaje de personas con más de diez fue en aumento.

Estos datos, más algunos casos de funcionarios individualizados, muestran que era posible desarrollar una carrera de largo plazo en la administración, tal como lo planteó Julio Heise. De hecho, es posible afirmar que, al menos en los casos estudiados, existió lo que podría definirse como un sistema de servicio civil moderno de facto. Tal como se expuso, entre 1880 y 1920 existió un grupo de funcionarios que hizo del trabajo en la administración su ocupación de por vida. Ello fue posible, por una parte, gracias a la definición de funciones y jerarquía de los empleados, junto con la fijación, a través de la ley, de remuneraciones y un sistema de jubilación capaces de asegurar ingresos tanto en el periodo activo como en el retiro del campo laboral. Más interesante aún, aunque la legislación no consagró un sistema de carrera capaz de resguardar la estabilidad, la práctica administrativa sí lo hizo. Aunque en el nombramiento de varios funcionarios, en especial los directivos, el Presidente de la República participaba, en otros la decisión era tomada por los jefes de oficina. El ejercicio de esta prerrogativa durante cuarenta años, muestra que los nombramientos y ascensos en el Tribunal de Cuentas, y la Dirección de Contabilidad fueron realizados sobre la base del respeto de la jerarquía de las plantas y la antigüedad. En el caso de Impuestos Internos, el criterio que primó fue el mérito, medido en pruebas de selección. Ello, muy probablemente, debió funcionar como un incentivo para que un grupo de personas se interesara en dedicar su vida laboral a una actividad que ofrecía estabilidad y opciones de obtener mejores oportunidades a través del

\footnotetext{
110 “Concurso de competencia para la provisión del empleo de sub-inspector de la Dirección de Impuestos Internos" y nómina sin título de aspirantes y puntaje, sin número, sin ciudad, en ARNAD, AMH, vol. 4189 "Dirección de Impuestos Internos 1910-1917".

${ }^{111}$ Véase, por ejemplo, Nota del Director de Impuestos Internos $N^{\circ} 1885$, Santiago, 24 de marzo 1914, en ARNAD, AMH, vol. 3807 "Dirección General de Impuestos Internos 1906-1914"; "Nómina del número de puntos que obtuvieron los candidatos aprobados en el concurso de contadores", sin número, sin ciudad, en ARNAD, AMH, vol. 4282 "Dirección de Impuestos Internos 1911-1913".

${ }^{112}$ Encina, Nuestra inferioridad..., op. cit., pp. 78-79, 163-164.
} 
tiempo. Clarificador de esto son el aumento progresivo del tiempo promedio de permanencia en las oficinas y los casos de funcionarios que, tras una vida completa en la administración, accedieron a la responsabilidad de ser jefe de oficina. A ello es necesario agregar que los funcionarios construyeron una identidad como empleados públicos ${ }^{113}$.

Aunque se requiere una investigación en profundidad al respecto, una primera mirada permite relativizar aquellas afirmaciones que plantean que con la dictación del primer estatuto administrativo, en 1925, comenzó un sistema de carrera en Chile. Si bien es cierto que los decretos de estatuto administrativo, dictados en 1925, 1927 y 1930, formalizaron un sistema de servicio civil moderno, ello se realizó a partir de la destrucción de la tradición y práctica administrativas del sistema que de facto operó con anterioridad. De hecho, tanto en 1923 (ley No 3921) como en 1926 y 1927 (leyes $N^{o} 4075$ y No 4113) se dictaron cuerpos normativos que apuntaron a la dictación de un estatuto administrativo, pero teniendo en vista la reducción del número de empleados (ello implicaba eliminar las garantías de estabilidad que, en la práctica, operaron en el periodo estudiado en este trabajo). Durante 1927, una gran cantidad de puestos fueron declarados vacantes por no ser necesarios ${ }^{114}$. Es decir, junto con propiciar la creación de un sistema de carrera para tecnificar la gestión estatal, como generalmente se destaca ${ }^{115}$, los actores de la época intentaron encontrar mecanismos para contener los gastos en remuneraciones. Ese objetivo estaba antes en la lista de prioridades que los esfuerzos de tecnificación. Un estudio en profundidad sobre esta cuestión permitiría comprender mejor tanto esta cuestión particular, sobre la gestión de personas en la administración pública, como la reforma administrativa de la década de 1920 en su conjunto.

Este artículo ha mostrado que, a partir de prácticas o instituciones informales, es posible establecer un sistema de servicio civil de facto. La literatura sobre servicio civil podría verse beneficiada de este trabajo para explorar por qué, por ejemplo, en casos como el presentado acá, es posible contar con un servicio civil que opera a partir de la tradición y por qué en otras ocasiones, sistemas formalizados a través de normas legales no logran operar correctamente ${ }^{116}$.

${ }^{113}$ Barría, “An Honourable Profession...”, op. cit.

${ }^{114} B D L G$, Santiago, Imprenta Nacional, 1927, pp. 249, 263, 271, 274, 277, 349, 357, 376, 411, 420, 449, $450,451,476,480,509,510,513,519,522,528,536,552,557,562,923,955,961,962,968,970,972,1042$, 1044, 1048, 1050, 1052, 1054, 1348, 1352, 1372, 1385, 1668, 1685, 1691.

${ }^{115}$ Patricio Silva, In the Name of Reason. Technocrats and Politics in Chile, University Park, Pennsylvania State University Press, 2008; Jaime Esponda, Pablo Ramírez: el chileno desconocido, Santiago, RIL Editores, 2013.

${ }^{116}$ Agustín Ferraro, "Una idea muy precaria: el nuevo servicio civil y los viejos designados políticos en Argentina”, en Latin American Research Review, vol. 41, № 2, Pittsburgh, 2008, pp. 165-182. 